\title{
Current contraceptive management in Australian general practice: an analysis of BEACH data
}

\section{Danielle Mazza \\ MD, FRACGP \\ Professor and Head \\ Christopher Harrison BPsych(Hons), MSocHlth Senior Research Analyst ${ }^{2}$}

Angela Taft

$\mathrm{BA}, \mathrm{MPH}, \mathrm{PhD}$, Associate Professor

Bianca Brijnath

BA(Hons), PhD

NHMRC Early Career Fellow

Helena Britt

BA, PhD,

Associate Professor and

Director

Melissa Hobbs

RN, MPH, PhD

Honorary Fellow

Kay Stewart BPharm(Hons), PhD Associate Professor

Safeera Hussainy BPharm(Hons), PhD Lecturer $^{4}$

1 Department of General Practice, Monash University, Melbourne, VIC

2 Family Medicine Research Centre, University of Sydney, Sydney, NSW.

3 Maternal and Child Health Research Centre, Latrobe University, Melbourne, VIC

4 Centre for Medicine Use and Safety, Monash University, Melbourne, VIC

Danielle.Mazza@ monash.edu

MJA 2012; 197: 110-114 doi: 10.5694/mjall.11599
$\mathrm{D}$ espite nearly $70 \%$ of Australian women of reproductive age using a contraceptive method, ${ }^{1}$ estimates are that over $50 \%$ of Australian women have had an unplanned pregnancy. ${ }^{2}$ This rate, similar to that in the United Kingdom $(30 \%)^{3}$ and United States $(49 \%),{ }^{4}$ may in part be explained by the fact that the combined oral contraceptive pill (COCP) remains the preferred method of contraception in Australia ${ }^{1,5,6}$ as it is in the $\mathrm{UK}^{3}$ and US. ${ }^{7}$

Clinical guidelines recommend increased availability and accessibility of emergency contraception and promotion of long-acting reversible contraception (LARC; eg, intrauterine devices and contraceptive implants). ${ }^{3,8}$ Emergency contraception has been available over-thecounter in Australia since $2004^{9}$ but this has had little effect on the actual use of emergency contraception. ${ }^{10}$ Most Australian women remain unaware of the over-the-counter availability of emergency contraception, have misconceptions about it, and want more information from their general practitioners. ${ }^{9,11}$

The uptake of LARC is also low in Australia, with only $1.2 \%$ of women using it. ${ }^{1}$ Benefits of LARC include minimal maintenance once in place, and long-term, effective contraception. Increasing access to LARC is a public health priority in the $\mathrm{UK}^{3}$ and $\mathrm{US}^{8}{ }^{8}$ but there is no clear policy on LARC in Australia.

While contraception and reproductive health are core aspects of general practice, in Australia little is known about contraceptive management by GPs, what occurs during a contraceptive consultation, and how this affects contraceptive use and reproductive health outcomes. Therefore, our aim in this study was to determine current management of contraceptive issues by GPs in Australia.

Abstrac

Objective: To determine current contraceptive management by general practitioners in Australia.

Design, setting and participants: Analysis of data from a random sample of 3910 Australian GPs who participated in the Bettering the Evaluation and Care of Health (BEACH) survey, a continuous cross-sectional survey of GP activity, between April 2007 and March 2011. Consultations with female patients aged 12-54 years that involved all forms of contraception were analysed.

Main outcome measures: GP and patient characteristics associated with the management of contraception; types of contraception used; rates of encounters involving emergency contraception.

Results: Increased age, ethnicity, Indigenous status and holding a Commonwealth Health Care Card were significantly associated with low rates of encounters involving management of contraception. The combined oral contraceptive pill was the most frequently prescribed method of contraception, with moderate prescription of long-acting reversible contraception (LARC), especially among women aged 34-54 years. Rates of consultations concerned with emergency contraception were low, but involved high rates of counselling, advice or education (48\%) compared with encounters for general

contraception ( $>20 \%$ )

Conclusion: A shift towards prescribing LARC, as recommended in clinical guidelines, has yet to occur in Australian general practice. Better understanding of patient and GP perspectives on contraceptive choices could lead to more effective contraceptive use.

\section{Methods}

We analysed data from the Bettering the Evaluation and Care of Health $(\mathrm{BEACH})$ program, collected from April 2007 to March 2011. BEACH is a continuous, paper-based, national study of GP activity in Australia. ${ }^{12}$ Each year, a national, rolling random sample of 1000 GPs each provides information for 100 consecutive consultations with consenting, unidentified patients. The University of Sydney Human Research Ethics Committee and the Australian Institute of Health and Welfare Ethics Committee have approved BEACH.

We restricted our analysis to encounters between GPs and female patients of reproductive age (defined as 12-54 years of age) and examined GP and patient characteristics, and up to four problems managed per consultation. For each problem, management data include medications, clinical treatments, procedures undertaken, pathology orders, and referrals. Problems managed at consultations were classified according to the International classification of primary care, 2nd edition (ICPC-2) ${ }^{13}$ and coded to more specific ICPC-2 PLUS terminology. ${ }^{14}$ General contraception was defined as including "Oral contraception" (ICPC-2 code W11), "Intrauterine contraception" (W12), "Female sterilisation" (W13), "Other female contraception" (W14) and "Reproductive medication" (W50). Emergency contraception was defined as "Post-coital contraception" (W10), "Fear of pregnancy" (W02) and "Unprotected sex, Female" (A23011).

The BEACH study uses a singlestage cluster design, with a cluster of consultations around each GP. In all analyses, we adjusted for this cluster using survey procedures in SAS statistical software (SAS Institute Inc, Cary, NC, USA). Statistical significance of differences was determined by nonoverlapping $95 \%$ CIs.

\section{Results}

From April 2007 to March 2011, 3910 GPs participated in $\mathrm{BEACH}$, recording 391000 patient encounters. Of these, 
1 Rate of contraceptive management at 114034 consultations with women aged 12-54 years according to patient characteristics

Rate per 1000 consultations $(95 \% \mathrm{Cl})$

\begin{tabular}{|c|c|c|c|}
\hline \multirow{2}{*}{ Patient characteristic } & & & \\
\hline & General contraception & Emergency contraception & Total contraception \\
\hline \multicolumn{4}{|c|}{ New to practice (missing data for 1218 consultations*) } \\
\hline Yes & $75.26(69.34-81.18)$ & $3.03(1.86-4.19)$ & $78.29(72.23-84.35)$ \\
\hline No & $58.5(56.68-60.33)$ & $0.90(0.71-1.10)$ & $59.41(57.57-61.25)$ \\
\hline \multicolumn{4}{|c|}{ Non-English speaking background? (missing data for 12678 consultations*) } \\
\hline Yes & $34.02(29.44-38.61)$ & $1.37(0.54-2.21)$ & $35.39(30.72-40.08)$ \\
\hline No & $62.60(60.60-64.59)$ & $1.06(0.84-1.28)$ & $63.65(61.63-65.67)$ \\
\hline \multicolumn{4}{|c|}{ Commonwealth Health Care Card? (missing data for 10204 consultations*) } \\
\hline Yes & $50.34(47.46-53.21)$ & $1.18(0.76-1.60)$ & $51.51(48.60-54.43)$ \\
\hline No & $63.58(61.36-65.79)$ & $1.08(0.83-1.32)$ & $64.65(62.41-66.89)$ \\
\hline \multicolumn{4}{|c|}{ Indigenous? (missing data for 12664 consultations*) } \\
\hline Yes & $43.80(31.75-55.84)$ & $1.04(0.00-2.46)$ & $44.83(32.48-57.19)$ \\
\hline No & $60.43(58.51-62.35)$ & $1.10(0.88-1.31)$ & $61.52(59.58-63.47)$ \\
\hline \multicolumn{4}{|c|}{ State (missing data for 2199 consultations*) } \\
\hline Australian Capital Territory & $70.24(56.35-84.13)$ & $1.66(0.00-3.57)$ & $71.90(57.03-0.87)$ \\
\hline New South Wales & $54.48(51.52-57.44)$ & $0.94(0.63-1.25)$ & $55.42(52.43-58.40)$ \\
\hline Victoria & $57.38(53.86-60.90)$ & $1.07(0.66-1.49)$ & $58.45(54.88-62.02)$ \\
\hline Queensland & $65.14(60.54-69.75)$ & $1.22(0.75-1.70)$ & $66.36(61.75-70.98)$ \\
\hline South Australia & $62.87(56.56-69.19)$ & $1.25(0.42-2.08)$ & $64.12(57.84-70.39)$ \\
\hline Western Australia & $68.75(62.37-75.12)$ & $1.14(0.45-1.83)$ & $69.88(63.41-76.35)$ \\
\hline Tasmania & $68.07(57.16-78.98)$ & $1.78(0.18-3.37)$ & $69.84(58.95-80.72)$ \\
\hline Northern Territory & $87.33(54.07-120.58)$ & $2.13(0.00-5.01)$ & $89.45(56.71-122.19)$ \\
\hline \multicolumn{4}{|c|}{ Rurality ${ }^{\dagger}$ (missing data for 2199 consultations*) } \\
\hline Major cities & $59.48(57.31-61.65)$ & $1.16(0.91-1.41)$ & $60.63(58.44-62.83)$ \\
\hline Inner regional & $61.16(57.21-65.12)$ & 0.94 (0.50-1.37) & $62.09(58.07-66.12)$ \\
\hline Outer regional & $63.70(56.75-70.65)$ & $1.07(0.42-1.72)$ & $64.76(57.71-71.81)$ \\
\hline Remote & $56.36(41.0-71.72)$ & $1.52(0.00-3.55)$ & $57.88(42.01-73.75)$ \\
\hline Very remote & $64.40(38.06-90.74)$ & $1.79(0.00-5.21)$ & 66.18 (39.91-92.46) \\
\hline
\end{tabular}

114034 (29.2\%) were with females aged 12-54 years: $7616(6.7 \%)$ with 12-17-year-olds, $17405(15.3 \%)$ with 18-24-year-olds, $27920(24.5 \%)$ with 25-34-year-olds, 29206 (25.6\%) with 35-44-year-olds and 31887 (28.0\%) with 45-54-year-olds.

Contraceptive problems (general or emergency) were managed at a rate of 6.1 per 100 consultations (95\% CI, 5.9-6.3). Women aged 18-24 years had the highest rate of management for general contraception, and this rate decreased with age. Similar trends were observed for emergency contraception management.

Female patients who were Indigenous, spoke a language other than English at home, held a Commonwealth Health Care Card or had been to the general practice before had significantly lower general contraceptive management rates (Box 1). Only one of the patient characteristics had a significant influence on emergency contraception management patients new to the practice were three times more likely than patients known to the practice to have emergency contraception managed (Box 1).

Female GPs managed general contraception more frequently than their male counterparts. GPs aged less than 35 years managed general contraception most often and those aged 55 years and older least often. GPs who held a Fellowship from the Royal Australian College of General Practitioners (RACGP) had higher rates of management of general contraception. GPs in solo practice managed general contraception less often than those working in larger practices (Box 2).

Medication was the most common form of general contraception, being prescribed, supplied, or recommended for over-the-counter purchase 90 times per 100 contraception problems managed. Most of the medications recorded were COCPs with combined levonorgestrel/ethinyloestradiol being the most frequently recorded individual medication, accounting for nearly half the medications for all age groups (Box 3). Drospirenone/ethinylestradiol and cyproterone/ethinyloestradiol (also COCPs) were more frequently recorded for 12-34-year-olds than those aged 35-54 years. The reverse was true for LARCs, with medroxyprogesterone and the levonorgestrel intrauterine device being recorded more often for 35-54-year-olds than for 12-34-year-olds. Copper intrauterine and ethinyloestradiol/etonogestrel devices were least often prescribed. For emergency contraception problems, levonorgestrel was the most frequently recorded medication.

Clinical treatments (primarily counselling, advice and education) were the next most common form of management, used at twice the rate in 
management of emergency contraception than general contraception (Box 4 ). The most frequent procedural treatments for general contraception were related to fitting or removing of a contraceptive device. Women aged 35-54 years had more procedural treatments in the management of their general contraception because of a significantly higher rate of local injection (for administration of medroxyprogesterone). Procedures were significantly fewer for emergency contraception problems, most being pregnancy tests and Pap smears. Women aged 35-54 years were referred for general contra- ceptive problems more often than 12 24-year-olds, with most referred to obstetricians and gynaecologists. There were no referrals recorded for emergency contraception problems. Only 5.9 pathology tests were ordered per 100 general contraception problems compared with 86.6 tests per 100

\section{Rate of contraceptive management at 114034 consultations with women aged 12-54 years according to general practitioner} characteristics

Rate per 1000 consultations ( $95 \% \mathrm{Cl}$ )

\begin{tabular}{|c|c|c|c|}
\hline General practitioner characteristic & General contraception & Emergency contraception & Total contraception \\
\hline \multicolumn{4}{|c|}{ Age (missing data for 604 consultations*) } \\
\hline$<35$ years & $75.07(68.02-82.12)$ & $1.22(0.45-1.99)$ & $76.30(69.19-83.41)$ \\
\hline $35-44$ years & $62.71(58.41-67.00)$ & $1.16(0.73-1.60)$ & $63.87(59.55-68.19)$ \\
\hline $45-54$ years & $61.46(58.50-64.43)$ & $1.33(0.94-1.72)$ & $62.80(59.78-65.82)$ \\
\hline$\geqslant 55$ years & $53.67(50.72-56.63)$ & $0.80(0.51-1.10)$ & $54.48(51.52-57.45)$ \\
\hline \multicolumn{4}{|l|}{ Sex (no missing data) } \\
\hline Male & $49.71(47.56-51.86)$ & $0.94(0.68-1.199)$ & $50.65(48.48-52.83)$ \\
\hline Female & $70.32(67.47-73.17)$ & $1.27(0.95-1.60)$ & $71.60(68.72-74.47)$ \\
\hline \multicolumn{4}{|c|}{ FRACGP status (missing data for 505 consultations*) } \\
\hline Yes & $63.43(60.77-66.09)$ & $1.22(0.91-1.53)$ & $64.66(61.98-67.34)$ \\
\hline No & $56.76(54.25-59.27)$ & $0.99(0.71-1.27)$ & $57.76(55.22-60.30)$ \\
\hline \multicolumn{4}{|c|}{ Practice size ${ }^{\dagger}$ (missing data for 635 consultations*) } \\
\hline 1 General practitioner & $46.82(38.33-55.32)$ & $0.88(0.02-1.75)$ & $47.71(39.11-56.30)$ \\
\hline 2-4 General practitioners & $55.50(51.05-59.94)$ & $0.68(0.28-1.08)$ & $56.18(51.70-60.65)$ \\
\hline 5-9 General practitioners & $65.11(61.08-69.14)$ & $1.10(0.65-1.54)$ & $66.21(62.14-70.29)$ \\
\hline 10-14 General practitioners & $60.48(53.96-66.99)$ & $1.87(0.98-2.76)$ & 62.35 (55.73-68.97) \\
\hline$\geqslant 15$ General practitioners & $65.02(56.28-73.77)$ & $0.72(0.00-1.53)$ & $65.75(57.07-74.42)$ \\
\hline \multicolumn{4}{|c|}{ Country of graduation (missing data for 205 consultations*) } \\
\hline Australia & $61.05(58.84-63.27)$ & $1.02(0.78-1.25)$ & $62.08(59.84-64.317)$ \\
\hline Overseas & $58.01(54.74-61.29$ & $1.34(0.91-1.77)$ & $59.36(56.05-62.67)$ \\
\hline
\end{tabular}

FRACGP $=$ Fellow of the Royal Australian College of General Practitioners.

* Missing data removed from denominator. † Collected for the 2009-2011 data period, which included 56873 consultations.

\section{Rate of contraceptive medication recorded by age group, 2007 to 2011}

Rate per 100 contraception problems managed $(95 \% \mathrm{CI})$

\begin{tabular}{|c|c|c|c|c|c|c|}
\hline \multirow[b]{4}{*}{ Contraceptive } & \multicolumn{6}{|c|}{ Rate per 100 contraception problems managed $(95 \% \mathrm{CI})$} \\
\hline & \multicolumn{5}{|c|}{ General contraception } & \multirow{3}{*}{$\begin{array}{c}\text { Emergency contraception } \\
\text { All ages } \\
12-54 \text { years }\end{array}$} \\
\hline & \multicolumn{4}{|c|}{ Age group } & \multirow{2}{*}{$\begin{array}{c}\text { All ages } \\
12-54 \text { years }\end{array}$} & \\
\hline & $12-24$ years & $25-34$ years & $34-44$ years & $45-54$ years & & \\
\hline Combined oral contraceptive pill* & $78.1(76.4-79.8)$ & $66.3(64.2-68.5)$ & $58.0(55.2-60.8)$ & $58.4(53.8-63.0)$ & $68.6(67.3-70.0)$ & $7.1(2.6-11.6)$ \\
\hline Levonorgestrel/ethinyloestradiol & $42.8(40.9-44.8)$ & $36.7(34.7-38.8)$ & $41.3(38.7-43.9)$ & $43.5(38.9-48.1)$ & $40.5(39.2-41.8)$ & $3.1(0.1-6.2)$ \\
\hline Drospirenone/ethinyloestradiol & $16.1(14.6-17.6)$ & $13.3(11.8-14.8)$ & $7.1 \quad(5.7-8.4)$ & $4.6(2.7-6.5)$ & $12.5(11.6-13.4)$ & $2.4(0.0-5.0)$ \\
\hline Cyproterone/ethinyloestradiol & $13.5(12.2-14.9)$ & $10.2(9.0-11.5)$ & $4.1(3.0-5.1)$ & $3.6(1.9-5.2)$ & $9.8(9.0-10.5)$ & $0.8(0.0-2.3)$ \\
\hline Norethisterone/ethinyloestradiol & $3.8(3.1-4.5)$ & $3.9(3.1-4.7)$ & $3.1(2.2-4.1)$ & $4.2(2.3-6.1)$ & $3.7(3.3-4.2)$ & 0 \\
\hline Long-acting reversible contraception & $11.8(10.5-13.1)$ & $15.4(13.8-17.0)$ & $20.3(18.2-22.5)$ & $20.8(17.2-24.4)$ & $15.4(14.5-16.4)$ & $0.8(0.0-2.3)$ \\
\hline Medroxyprogesterone $^{\dagger}$ & $6.1(5.2-7.1)$ & $8.6(7.4-9.8)$ & $11.6(9.9-13.3)$ & $13.0(9.9-16.1)$ & $8.6(7.9-9.3)$ & 0 \\
\hline Etonogestrel ${ }^{\ddagger}$ & $5.3(4.4-6.3)$ & $4.8(3.8-5.7)$ & $4.8(3.7-6.0)$ & $3.2(1.6-4.7)$ & $4.9(4.3-5.5)$ & $0.8(0.0-2.3)$ \\
\hline Levonorgestrel intrauterine device & $0.3(0.1-0.6)$ & $1.9(1.3-2.5)$ & $3.7(2.6-4.8)$ & $4.6(2.8-6.5)$ & $1.9(1.4-2.3)$ & 0 \\
\hline Copper intrauterine device & $0.0(0.0-0.1)$ & $0.1 \quad(0.0-0.3)$ & $0.2(0.0-0.4)$ & 0 & $0.1 \quad(0.0-0.2)$ & 0 \\
\hline Other & $4.1 \quad(3.3-4.9)$ & $7.3(6.2-8.4)$ & $7.2(5.8-8.6)$ & $5.3(3.2-7.3)$ & $5.9(5.3-6.5)$ & $48.0(38.0-58.0)$ \\
\hline Levonorgestrel & $1.2(0.8-1.6)$ & $3.9(3.1-4.8)$ & $3.8(2.8-4.8)$ & $2.5(1.1-3.9)$ & $2.7(2.3-3.1)$ & $43.3(34.0-52.6)$ \\
\hline Ethinyloestradiol/etonogestrel device $e^{\xi}$ & $1.2(0.7-1.6)$ & $1.3(0.8-1.8)$ & $1.4(0.8-2.0)$ & 0 & $1.2(0.9-1.5)$ & 0 \\
\hline Total medications & $94.0(92.9-95.2)$ & $89.0(87.5-90.5)$ & $85.5(83.4-87.6)$ & $84.5(81.1-87.8)$ & $89.9(89.0-90.9)$ & $55.9(45.4-66.4)$ \\
\hline
\end{tabular}

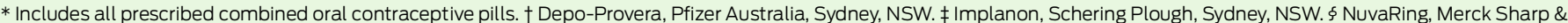
Dohme (Australia), Sydney, NSW. 


\begin{tabular}{|c|c|c|c|c|c|c|}
\hline \multirow[b]{4}{*}{ Clinical treatment } & \multicolumn{6}{|c|}{ Rate per 100 contraceptive problems managed $(95 \% \mathrm{Cl})$} \\
\hline & \multicolumn{5}{|c|}{ General contraceptive } & \multirow{3}{*}{$\begin{array}{c}\text { Emergency contraceptive } \\
\text { All ages } \\
12-54 \text { years }\end{array}$} \\
\hline & \multicolumn{4}{|c|}{ Age group } & \multirow{2}{*}{$\begin{array}{c}\text { All ages } \\
12-54 \text { years }\end{array}$} & \\
\hline & $12-24$ years & $25-34$ years & $35-44$ years & $45-54$ years & & \\
\hline Counselling/advice/education & $24.3(22.2-26.4)$ & $17.3(15.5-19.2)$ & $15.9(13.9-18.0)$ & $14.9(11.3-18.5)$ & $19.6(18.3-20.9)$ & $48.0(38.0-58.1)$ \\
\hline \multicolumn{7}{|l|}{ Procedures } \\
\hline Hormone implant & $5.2(4.3-6.2)$ & $5.1(4.0-6.1)$ & $6.4(4.9-7.8)$ & $5.0(2.8-7.3)$ & $5.4(4.7-6.1)$ & 0 \\
\hline Local injection* & $3.4(2.7-4.2)$ & $5.0(4.1-6.0)$ & $6.6(5.2-8.0)$ & $8.0(5.6-10.4)$ & $4.9(4.4-5.5)$ & $0.8(0-2.3)$ \\
\hline Contraceptive device fitting/supply/removal & $0.4(0.2-0.7)$ & $1.7(1.1-2.4)$ & $2.0(1.3-2.8)$ & $3.4(1.6-5.2)$ & $1.4(1.0-1.7)$ & 0 \\
\hline Pap smear & $1.1(0.7-1.6)$ & $1.6(1.1-2.1)$ & $0.8(0.4-1.3)$ & $1.1(0.1-2.0)$ & $1.2(0.9-1.5)$ & $1.6(0-3.8)$ \\
\hline Pregnancy test & $0.5(0.2-0.8)$ & $0.8(0.4-1.1)$ & $0.6(0.2-0.9)$ & $0.2(0-0.6)$ & $0.6(0.4-0.8)$ & $5.5(1.5-9.6)$ \\
\hline Total procedures & $11.4(10.0-12.8)$ & $15.3(13.6-17.0)$ & $17.5(15.2-19.7)$ & $18.3(14.6-21.9)$ & $14.4(13.4-15.5)$ & $8.7(3.2-14.1)$ \\
\hline \multicolumn{7}{|l|}{ Referrals } \\
\hline Obstetrician/gynaecologist & $0.3(0.1-0.5)$ & $1.7(1.1-2.2)$ & $4.1 \quad(3.1-5.2)$ & $4.4(2.6-6.3)$ & $1.8(1.5-2.2)$ & 0 \\
\hline Total referrals & $0.7(0.4-1.1)$ & $2.1(1.6-2.7)$ & $5.7(4.5-7.0)$ & $5.5(3.4-7.5)$ & $2.6(2.2-3.0)$ & 0 \\
\hline \multicolumn{7}{|l|}{ Pathology tests } \\
\hline STI tests ${ }^{\dagger}$ & $1.5(0.9-2.1)$ & $0.5(0.2-0.9)$ & $0.3(0-0.7)$ & $0.4(0-1.0)$ & $0.9(0.6-1.1)$ & $53.5(31.2-75.9)$ \\
\hline Total pathology tests ${ }^{\ddagger}$ & $5.2(3.9-6.4)$ & $6.4(4.9-8.0)$ & $5.5(3.6-7.5)$ & $8.0(2.9-13.1)$ & $5.9(4.9-6.8)$ & $86.6(55.8-117.4)$ \\
\hline
\end{tabular}

$\mathrm{STI}=$ sexually transmitted infection.

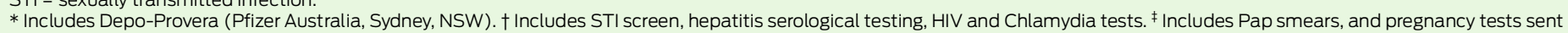
to pathology laboratories.

emergency contraception problems; most of these were tests for sexually transmitted infections (STIs).

\section{Discussion}

This study on current contraceptive management by GPs in Australia provides important insights into the high rates of unplanned pregnancy that exist despite patients reporting high rates of contraceptive use.

Patient factors such as age, ethnicity, Indigenous status and holding a Commonwealth Health Care Card were associated with lower rates of contraceptive consultations. Rates of management of general contraception and emergency contraception were highest among young women (18-24 years), and declined with womens' age. This could be because older women are more likely to use contraceptive methods that do not require them to regularly fill prescriptions (unlike younger women who tend to rely most commonly on COCPs). However, these lower rates of encounter may also account for the increasing levels of unplanned pregnancy and abortion being seen in women in this age group. ${ }^{15,16}$

Women who spoke a language other than English at home had a rate of management of general contraception that was half that of women from
English-speaking households. Local $^{3,17}$ and international ${ }^{18,19}$ data show that ethnicity influences the type of contraception used. The popularity of the COCP is lower among women of non-English-speaking background than locally born women. ${ }^{6,18-20}$

Supporting previous Australian studies, $1,5,6,17$ we found high use of the COCP, moderate use of LARC (especially among 34-54 year olds), and low rates of management of emergency contraception. This probably reflects age and life-stage appropriateness of the agents being prescribed. $^{21}$ The COCP has been found to be the preferred method of contraception before and between pregnancies, but its rate of use decreases with age and with higher numbers of pregnancies., ${ }^{5,22}$ Middleaged women tend to use longer-term methods of contraception when no further pregnancies are desirable, ${ }^{5}$ and this strategy requires fewer visits to GPs.

GPs' views influence the advice they give to potential users, the availability of particular contraceptive methods and the type of contraception selected by patients. ${ }^{3}$ Lack of familiarity among GPs with inserting and removing intrauterine devices (IUDs) and implants resulting from a lack of appropriate technical training and from medical indemnity insurance costs may be factors exacerbating difficulties women have in obtaining information about LARCs. ${ }^{23-25}$ Women are also poorly advised or have misconceptions that IUDs are unsuitable, even when they meet the medical eligibility criteria. ${ }^{17}$ However, the gradual rise in the use of implants among younger women, suggests a possible trend towards LARC. $^{22}$

Young women (aged 18-24 years) had the highest rate of management of emergency contraception, but overall rates of management of emergency contraception in general practice is low. This may be because women can obtain emergency contraception overthe-counter, or because GPs are not integrating this form of contraception, including advance prescription of emergency contraception, into consultations involving sexual and reproductive health. Many women who received emergency contraception from GPs in our study, also received counselling and tests for STIs. The value of these additional services should be weighed against increased accessibility though over-the-counter purchase.

Women's preference to see female GPs for matters related to reproduction and contraception is well-established. ${ }^{26-28}$ Other GP characteristics 
associated with higher rates of contraceptive management, such as younger age and holding an RACGP Fellowship, may reflect outcomes of better training in these graduates.

The lower rates of counselling and advice provided in managing general contraception compared with emergency contraception may reflect the need for regular visits for repeat prescriptions, and that GPs may have provided advice and counselling in earlier consultations but opportunities to improve health literacy in sexual and reproductive health may be being missed.

The statistical reliability and validity of BEACH has been established ${ }^{29}$ and results from this study are rigorous. Nevertheless it has limitations; more frequent visits to GPs to obtain COCP prescriptions compared with a single visit for emergency contraception means that our study sample automatically detected more cases of COCP than emergency contraception. A similar limitation applies to comparing COCP use with LARC.

Further research is needed into GPs' use of consultations with women to manage contraception, (particularly emergency contraception), to undertake related health activities (eg, Pap smears and STI tests). Qualitative work examining patient and GP perspectives on contraception will yield better insight on how to facilitate a shift to more efficacious long-term contraceptives.

Competing interests: No relevant disclosures. Received 15 Dec 2011, accepted 19 Apr 2012.
1 Richters J, Grulich AE, de Visser RO, et al. Sex in Australia: contraceptive practices among a representative sample of women. Aust N Z J Public Health 2003; 27: 210-216.

2 Marie Stopes International Australia. Real choices: women, contraception and unplanned pregnancy. Melbourne: MSIA, 2008. http:// www.mariestopes.org.au/research/australia/ australia-real-choices-key-findings (accessed Apr 2012).

3 National Collaborating Centre for Women's and Children's Health. Long-acting reversible contraception: the effective and appropriate use of long-acting reversible contraception. London: RCOG Press, 2005. Commissioned by the National Institute for Health and Clinical Excellence 2005. http://guidance.nice.org.uk/ CG30/Guidance/pdf/English (accessed Apr 2012).

4 Finer LB, Henshaw SK. Disparities in rates of unintended pregnancy in the United States, 1994 and 2001. Perspect Sex Reprod Health 2006; 38: 90-96.

5 Read C, Bateson D, Weisberg E, Estoesta J. Contraception and pregnancy then and now: examining the experiences of a cohort of mid-age Australian women. Aust N Z J Obstet Gynaecol 2009; 49: 429-433.

6 Yusuf F, Siedlecky S. Patterns of contraceptive use in Australia: analysis of the 2001 National Health Survey. J Biosoc Sci 2007; 39: 735-744.

7 Trussell J, Wynn LL. Reducing unintended pregnancy in the United States. Contraception 2008; 77: 1-5.

8 National Research Council. Initial national priorities for comparative effectiveness research. Washington, DC: National Academies Press, 2009. http://www.nap.edu/catalog.php?record id=12648 (accessed Apr 2012).

9 Hussainy SY, Stewart K, Chapman CB, et al. Provision of the emergency contraceptive pill without prescription: attitudes and practices of pharmacists in Australia. Contraception 2011; 83: 159-166.

10 Novikova N, Weisberg E, Fraser IS. Does readily available emergency contraception increase women's awareness and use? Eur J Contracept Reprod Health Care 2009; 14: 39-45.

11 Hobbs MK, Taft AJ, Amir LH, et al. Pharmacy access to the emergency contraceptive pill: a national survey of a random sample of Australian women. Contraception 2011; 83: 151-158.

12 Britt H, Miller GC, Charles J, et al. General practice activity in Australia 2010-11. Sydney: Sydney University Press, 2011.

13 Classification Committee of the World Organization of Family Doctors. ICPC-2:
International classification of primary care. 2nd ed. Oxford: Oxford University Press, 1998

14 Britt $\mathrm{H}$. A new coding tool for computerised clinical systems in primary care--ICPC plus. Aust Fam Physician 1997; 26 Suppl 2: S79-S82.

15 Abigail W, Power C, Belan I. Changing patterns in women seeking terminations of pregnancy: a trend analysis of data from one service provide 1996-2006. Aust N Z J Public Health 2008; 32: 230-237.

16 Rowe HJ, Kirkman M, Hardiman EA, et al. Considering abortion: a 12-month audit of records of women contacting a Pregnancy Advisory Service. Med J Aust 2009; 190: 69-72.

17 Bateson D, Harvey C, Williams J, Black KI. Intrauterine contraception: why are so few Australian women using this effective method? [letter]. Med J Aust 2011; 194: 324

18 Saxena S, Copas AJ, Mercer C, et al. Ethnic variations in sexual activity and contraceptive use: national cross-sectional survey. Contraception 2006; 74: 224-233.

19 Ursin G, Wu AH, Hoover RN, et al. Breast cancer and oral contraceptive use in Asian-American women. Am J Epidemiol 1999; 150: 561-567.

20 Yusuf F, Siedlecky S. Contraceptive use in Australia: evidence from the 1995 National Health Survey. Aust N Z J Obstet Gynaecol 1999; 39: 58-62.

21 Forrest JD. Timing of reproductive life stages. Obstet Gynecol 1993; 82: 105-111.

22 Lucke JC, Watson M, Herbert D. Changing patterns of contraceptive use in Australian women. Contraception 2009; 80: 533-539.

23 Mazza D. Take a fresh look at IUDs. Things have changed. Aust Fam Physician 2002; 31: 903-907.

24 Glasier A, Scorer J, Bigrigg A. Attitudes of women in Scotland to contraception: a qualitative study to explore the acceptability of long-acting methods. J Fam Plann Reprod Health Care 2008; 34: 213-217.

25 Forrest JD. US women's perceptions of and attitudes about the IUD. Obstet Gynecol Surv 1996; 51 (12 Suppl): S30-S34.

26 Harrison CM, Britt HC, Charles J. Sex of the GP--20 years on. Med J Aust 2011; 195: 192-196.

27 Young AF, Byles JE, Dobson AJ. Women's satisfaction with general practice consultations. Med J Aust 1998; 168: 386-389.

28 Bryson L, Warner-Smith P. Choice of GP: who do young rural women prefer? Aust J Rural Health 1998; 6: 144-149.

29 Britt $H$, Miller G, Bayram C. The quality of data on general practice - a discussion of BEACH reliability and validity. Aust Fam Physician 2007; 36: 36-40.

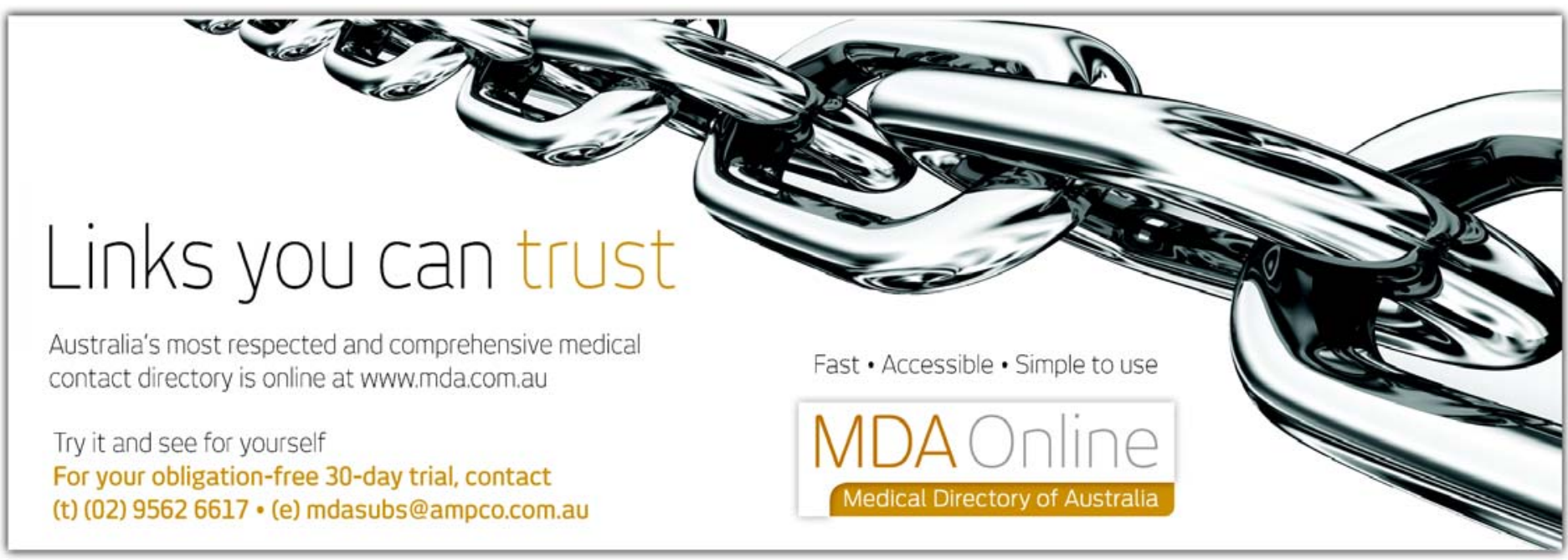


NT Health 